\section{Kompass \\ Ophthalmologie}

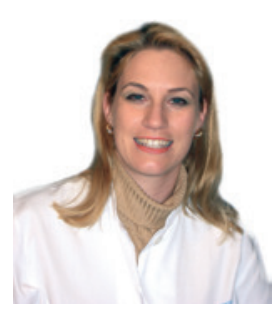

\section{Nicole Eter}

Klinik für Augenheilkunde,

Universitätsklinikum Münster, Münster, Germany

Dear Readers,

20 years of EURETINA mean 20 years of progress in retinology in Europe. EURETINA (European Society of Retina Specialists) was founded in 1999 to promote research in retinology, vitreoretinal surgery and macular diseases in Europe, and to provide a platform for scientific exchange. EURETINA was founded in 2000 at the «Ratskeller» in Hamburg, Germany. The founding members were, and are, colourful personalities in this field:

- August Deutman (Netherlands),

- Jean-Jacques DeLaey (Belgium),

- Krystyna Pecold (Poland),

- Gisbert Richard (Germany),

- Gisele Soubrane (France) and

- Borja Corcóstegui (Spain).

The first EURETINA congress was held in Hamburg in 2001. The number of participants has grown over the years, from 211 to over 5,000. Thus, the catchment area of the annual EURETINA Congress is much larger

\title{
20 years of EURETINA: 20 years of progress
}

than Europe itself: participants from all five continents attend the conference every year.

Through active exchange, EURETINA supports new diagnostic developments, advances in vitreoretinal surgery, development and application of new pharmacotherapies, and current strategies in the treatment of age-related macular degeneration. A dedicated chapter of the organisation is committed to the continuing education of young vitreoretinal surgeons and retina specialists.

Who would have thought that the 20th anniversary of EURETINA would end up being as extraordinary as it is: because of COVID-19, a typical congress with on-site attendance was not possible. Thus, EURETINA has taken up the challenge to organise a virtual conference. The anniversary event will comprise three days of events and more than 50 sessions.
20 years of EURETINA mean 20 years of progress in knowledge and treatments of retinal diseases. Some of these advances are presented in this supplemental issue. The entire era of anti-VEGF injections falls into these 20 years. A meta-analysis in this issue presents the effects of intravitreal ranibizumab therapy on visual acuity in patients with macular oedema. Cardinal surgical topics such as vitrectomy for rhegmatogenous retinal detachment, prognostic factors of surgery for epiretinal gliosis, and register analysis of eye injuries caused by fireworks are presented in this journal. We also dare to take a look into the future: how can self-learning machines analyse fundus images in order to identify systemic risk factors such as high blood pressure?

I hope you, dear readers, enjoy reading this issue. information@karger.com @ 2020 S. Karger GmbH, Freiburg www.karger.com/kop
Univ.-Prof. Dr. Nicole Eter

Klinik für Augenheilkunde

Universitätsklinikum Münster

Domagkstraße 15, 48149 Münster, Germany

nicole.eter@ukmuenster.de 